\title{
A Comparative Study of Stressors in Medical and Nursing Students of Shiraz University of Medical Sciences and how they Correlate with Their Academic Progress: A Cross-Sectional Study
}

\author{
Dr. Nahid Zarifsanaiey \\ Center of Excellence for e-Learning in Medical Sciences, Shiraz University of Medical Sciences, Shiraz, Iran \\ Email: sanaieyn@sums.ac.ir \\ Dr. Farhad Pakdel
}

Department of English, School of Paramedical Sciences, Shiraz University of Medical Sciences, Shiraz, Iran Corresponding Author. Email: ffpakdel@sums.ac.ir

\author{
Doi:10.5901/mjss.2015.v6n6s6p388
}

\section{Abstract}

Education at the university level is obviously stressful. The general aim of this paper is to study the correlation between stressful areas and students' academic progression at the Shiraz University of Medical Sciences. This is a cross-sectional research study. Three hundred and fifteen nursing and medical students were chosen by stratified random sampling. This data was collected via a questionnaire, which included demographics, stressors at educational, clinical and personal areas and supportive sources while the subjects cope with stress. To determine validity of the questionnaire, content and constructive validity were used. The reliability of the questionnaire was estimated by using Cranach's $\boldsymbol{\alpha}$ in educational (93\%), clinical (85\%) and personal (90\%) areas. The statistical method which was applied in this study included inferential and descriptive analysis. Results included that most students presented mild stress in educational, clinical and personal areas, although it was more noticeable in clinical area. The level of stress decreased in educational and clinical areas with increasing age and it reached the height in these areas in the subjects under the age of $20(P=0.003)$. There was more stress in females than males in educational and clinical areas $(P=0.003)$. There was more stress in the students of nursing than students of medicine in clinical area $(P=0.04)$. The level of stress in the subjects who were satisfied with their academic course was lower than subjects who were dissatisfied in clinical area. $(p=0.004)$. There was no significant correlation between academic progression and level of stress at educational, personal and clinical areas. Supportive source were mostly parents, the performance of religious duties and the means to find peace, friends and classmates, brothers and sisters, counsellors, and relatives. The results also indicated that some of the students did not seek help during stress and remained speechless. Considering the fact that most of the subjects presented stress in clinical area, the sources of stress in students, particularly stress caused by educational and clinical areas, must be evaluated carefully. On the other hand, it is necessary to teach students how to reduce and cope with stress.

Keywords: stressful areas, educational, clinical and personal areas, coping strategy, nursing students, medical students.

\section{Introduction}

Stress is an important part of our daily life. Educating at university is a stressful experience. Although mild stress is claimed to be desirable to improve student creativity and success, stress can affect student behaviour and interpersonal skills, decrease his/her learning capability and academic progression, and even endanger his/her health (Ainslie et al., 1996; Lee, et al. 2001). There has been research on stress from many years ago and various stressful circumstances and their motives have been studied. Heingli and Peter believe that stress can affect both psych and soma and decrease considerably they effort to achieve things and lead to failure. Students start the university on entering adolescence which is a highly stressful age. At this age, young learners who are entering adolescence are suddenly exposed to educational challenges such as facing new lecturers, heavy homework's, new texts and various exams. At the same time medical students need to make use of their education at clinical and health care centres which is a highly stressful experience. Inability to cope these stressors may lead to student academic failure or he may drop his education which both of them can affect the quality and quantity of health care. Highly stressful students can influence health care centres and workers negatively and trouble patient recovery. On the other hand, continuing of stress can lead to high blood pressure, sleeplessness, tachycardia, immune deficiency and even premature death. Moreover, it is said that the more students are 
stressed, the more worsened they become in education (Elani et al., 2014)

Researchers have studied the effects of stress on the students of Medical Sciences. These studies indicate that negative effects of stress usually involve the students as well as his/her family members, classmates and patients (Tuinman et al., 2004). Another study focusing on stress in female nursing students during their first clinical experience indicated that there was a significant difference between expected stress and the real levels of stress at the clinical center (Admi et al., 1997). Another study indicated that students are basically stressed due to insufficient knowledge and professional skill and patients care (Sheu et al., 2002). Since, at this age, students are developing self- confidence and high levels of stress can affect their health, quality of life, academic progression and preparation to admit their future role in job negatively, it is important to concentrate on stress and its consequences and adopt ways to avoid it. The first step to reduce stress is to identify stressors and student's preparation to assume their future role appropriately necessitates identification of stressors which prevent optimal performance (Pozos et al., 2008).

Understanding stressors in educational area of students of medical sciences specially nursing and medical students who face clinical experiences extensively enables us to find ways and effective methods of coping stress and its consequences. Supporting students physically, psychologically and socially to cope stress improves their health and effectiveness, prevents waste of time and energy in students and teaching staff and facilitates and enriches the process of education for students and teaching for school instructors. Another major factor is the mechanism to cope with stressors, because it is impossible to avoid all stressful circumstances and it is psychologically unhealthy to avoid all stressors and don't experience them and don't prepare to cope with them. It is impossible to avoid stress completely; therefore we must learn how to cope with stressors effectively (Nandi et al., 2012).

Considering the bad effect of stress on their students' academic progression, researchers decided to evaluate stressors and their correlation with students' academic progression in nursing and medical students so that they can plan the correct performance, reinforcement of motivation and achievement of the goals of education according to the results. The general aim of this research is to determine stressors in medical and nursing students and their correlation with students' academic progression and course satisfaction.

\section{Methods}

The present research was an applied and cross-sectional research study. The study included third semester and above students of nursing and medical schools (1270 students). 315 students were chosen by stratified random sampling as subjects of the research. The inclusion criteria were third semester and above students of nursing at both graduate and post-graduate level and general medicine because normally students start clinical area around this stage and a tendency to take part in the research. Students who had changed their subject during the last two semesters were excluded. The researchers set a questionnaire to collect data which determine stressors in medical and nursing students. The questionnaire contained three sections; section one included demographic features (9 items). Section two included stressors in educational, clinical and personal areas (35 items). and section three included supportive sources while facing stress ( 7 items) which was set based on five-point Likert scale (always, often, usually, rarely, never). To determine validity of the tool besides content validity which was performed by seeking opinions from 15 counsellors and specialists in psychology, factor analysis was also used to evaluate constructive validity of the tool. The following table presents the results of the factor analysis in each of the three areas (Table 1).

Table 1. Factor analysis in each of the three areas

\begin{tabular}{|l|c|}
\hline Small-scale & Alpha coefficient \\
\hline Educational area & $43 / 84$ \\
\hline Clinical area & $44 / 33$ \\
\hline Personal area & $55 / 49$ \\
\hline
\end{tabular}

The reliability of the questionnaire for evaluating each area of stress through Cranach's $\alpha$ is as follows: educational area (93\%), clinical area (85\%), and personal area (90\%).

\subsection{Ethics statement}

The study was reviewed and approved by Local Research Ethics Committee of Shiraz University of Medical Sciences (Ethics code: EC- 84-2658). The edited questionnaire was distributed among the students in person. The researchers 
informed all students who participated in the study about the objectives of the study and they had been given the chance to discuss any questions or issues then written informed consent was obtained from each participant. Ethical Considerations each participant's information was given a secret code and saved as confidential. On average, participants took 5-10 minutes to complete each study. The data were analysed using the statistical package for social sciences (spss), version 16. Results were presented in frequency tables. The chi-squared test was used for bivariate analysis of qualitative variables. A P value of $<0.05$ was considered significant.

\section{Results}

Out of 315 students who were the subjects of this study, medical and nursing students were $144(45.7 \%)$ and 171 (54.2\%) respectively. The study included $239(75.9 \%)$ female and $76(24.1 \%)$ male subjects. 91 (28.8\%) subjects were under 20 years of age, 208 (66.2\%) between $20-29$ and $16(5 \%)$ above $29.258(81.9 \%)$ subjects were single , $51(16.2 \%)$ married, 1(0.3\%) widow/widower and 5(1.6\%) divorcee. $144(45.7 \%)$ subjects studied general medicine, $43(13.6 \%)$ at post-graduate nurse and $128(40.7 \%)$ at graduate nurse. $185(58.7 \%)$ subjects lived at hostel and $130(41.2 \%)$ with family. The first specific aim of the study was to determine stressors in the students of the University of Medical Sciences. Stressors were evaluated in educational, clinical and personal areas (Table 2).

Table 2. Distribution of students based on stressors rate in educational, clinical and personal areas.

\begin{tabular}{|l|c|c|c|}
\hline Stressors & Low stress & Moderate stress & High stress \\
\hline Educational area & $199(58.5 \%)$ subjects & $123(36.2 \%)$ subjects & $18(5.4 \%)$ subjects \\
\hline Clinical area & $210(61.8 \%)$ subjects & $103(30.3 \%)$ subjects & $27(7.9 \%)$ subjects \\
\hline personal area & $248(72.9 \%)$ subjects & $82(24.1 \%)$ subjects & $10(2.9 \%)$ subjects \\
\hline
\end{tabular}

The data indicated that most students showed low stress in all area. Students who showed moderate stress were mostly in educational area $123(36.2 \%)$ and students with high stress in clinical area 27(7.9\%).

The researchers studied correlation between stressors and students features. There was no significant correlation between stressors and personal areas. Table 3 shows correlation of stressors in educational and clinical areas with demographic variables.

Table 3. Correlation between stressors (educational and clinical areas) and students' demographic variables.

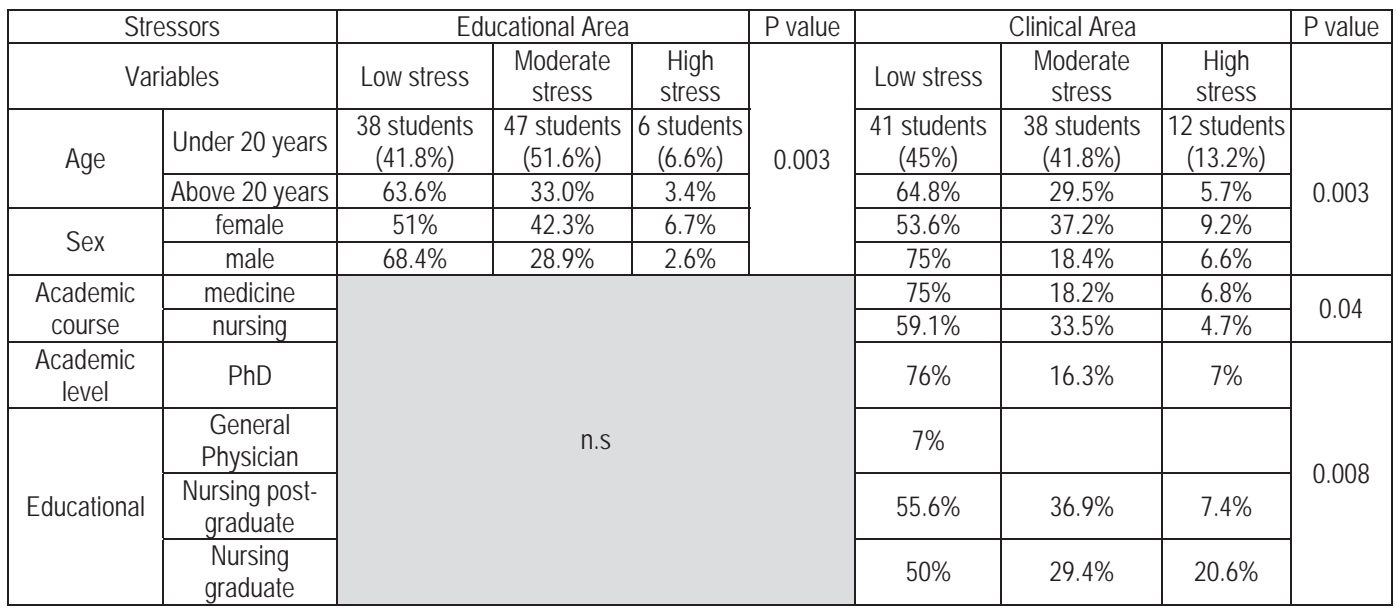

As indicated in table 3 there is a significant correlation between age group and the level of stress in both educational and clinical areas. The chi-squared test showed a significant correlation between age group and stress in educational and clinical areas_the more student grew old, the less stressed he/she became $(P=0.003)$ _ whereas there was no significant correlation between age and the level of stress in personal area. The chi-squared test also indicated a significant 
correlation between sex and the level of stress in educational and clinical areas so that the level of stress among women was higher in these areas $(P=0.003)$ but there was no significant correlation between sex and the level of stress in personal area. The correlation between academic course and areas of stress was evaluated. There was a significant correlation between academic course and the level of stress in clinical area so that the level of stress was higher among nursing students than medical students $(\mathrm{p}=0.04)$. There was no significant correlation between academic course and the level of stress in educational and personal areas. The correlation between academic level and areas of stress was also evaluated. The chi-squared test showed a significant correlation between academic level and the level of stress in clinical area so that the level of stress in graduate level was higher than other academic levels $(p=0.008)$. There was no significant correlation between academic level and the level of stress in educational and personal areas. The correlation between marital status and areas of stress was evaluated. The results indicated no significant correlation between marital status of the subjects and the level of stress. There was no significant correlation between residential place of the students and the three areas of stress. The chi-squared test didn't show a significant correlation between stressors and students features in personal area.

One of the aims of the study was to determine correlation between academic progression and the level of stress. To determine academic progression, the researchers used the student's means in the last two semesters. But there was no significant correlation between academic progression and the level of stress in all the three educational, personal and clinical areas. The next aim was to determine correlation between course satisfaction and the level of stress in educational, clinical and personal areas. Regarding academic course satisfaction, 79 (25.6\%) students were highly satisfied, $165(53.6 \%)$ to some extent, $45(14.6 \%)$ less satisfied and $19(6.2 \%)$ were totally dissatisfied. There was a significant correlation between course satisfaction and the level of stress in clinical area but researchers found no significant correlation between course satisfaction and the level of stress in educational and personal areas. Students who were satisfied with the academic course showed lower stress in clinical area $(p=0.004)$. The results also indicated no significant correlation between course satisfaction and type of course (subject). The last specific aim of the study was to determine supportive sources. The researchers studied supportive sources used by students during stress in order of priority (table 4).

Table 4. Students Supportive Sources in order of priority

\begin{tabular}{|l|c|}
\hline Supportive sources & Priority \\
\hline Seeking help from parents & 1 \\
\hline The performance of religious duties and the means to find peace & 2 \\
\hline Friends and classmates & 3 \\
\hline Brother and sister & 4 \\
\hline Counsellor & 5 \\
\hline Relatives & 6 \\
\hline
\end{tabular}

As indicated in table 4, $106(33.7 \%)$ students sought help from parents, 65 (20.6\%) from religious duties, 23 (7.3\%) from brothers and sisters, 33 (10.5\%) from classmates, 18 (5.7\%) from counsellors and $9(2.8 \%)$ from relatives in the first place while facing stress. Also, 46 (14.6\%) students didn't seek help from any supportive source during stress. Of course, the data indicated no significant correlation between supportive sources and the level of stress in all the three areas.

\section{Discussion}

In today's world, the speed of changes and human experiences has increased significantly and stresses and strains have dominated human life and it is unlikely to stay away from stress or remove stressors. Therefore, it is necessary to identify stressors. Students are frequently exposed to stresses and strains of life. The general aim of this paper was to study the correlation between stressors and students' academic status in nursing and medical students. The stressors were studied in educational, clinical and personal areas. The results indicated that most students had low stress in all the three areas, although it was higher in clinical area than the other two areas. Research activities have indicated that job training and clinical experience are stressful (Yonge et al., 2002; Sanaiey 2014).

Another finding of the present study indicated the correlation between age group and the level of stress. The level of stress in educational and clinical areas decreased with increasing age and the highest level of stress in these two areas was found in subjects under 20 years of age. The level of stress was also higher in lower academic levels than higher academic levels $(p=0.008)$. Perhaps, one of the reasons is that lower academic level students are normally 
younger in age. Research activities have indicated that types of stressors vary with increasing age. It seems that humans gain experiences as they grow old and these and other people experiences can reduce different types of stress such as job and educational status (Chang et al., 2007). The study also indicated a higher level of stress in female than male subjects in both educational and clinical areas. Baykan (2012) in his study reported no difference in the level of stress between female and male subjects which is different from the present study. But the results of some studies are compatible with the results of the present study].

The study evaluated the correlation between academic course and the areas of stress. There was no significant correlation between academic course and the level of stress in educational area. There was a significant correlation between academic course and the level of stress in clinical area and the level of stress in nursing students was higher than medical students $(p=0.04)$. Basically, nursing and caring patient is stressful by itself and clinical experiences are the most stressful problem for nursing students. A study was conducted to determine stressors in clinical area seeking the viewpoint of nursing students of Bagheyatollah... and Tehran schools. The results indicated that the main tension for students was patient physical care. Moreover, hospital environment, interaction with clinical and educational personnel in training environments and relationship between student and patient and his/her family members constituted stressors(Edwards et al., 2014). One study focusing on stress in female nursing students during their first clinical experience indicated a significant difference between expected stress before starting clinical area and the real level of stress during their clinical experience (Torshizi et al., 2011). Another study indicated that basically students are stressed due to insufficient knowledge and professional skills and also patient's care (Nicolescu et al., 2013; Bughi et al., 2006; Brahmbhatt et al., 2013).

Course satisfaction also influences the level of stress. The results of this study indicated a lower level of stress in clinical area in students who were satisfied with their academic course $(p=0.004)$. The study also evaluated the students supporting sources. The results indicated that supportive sources to cope with stress in order of priority included: seeking help from parents, the means to find peace and performance of religious duties, friends and classmates, sister and brother and counselor and a considerable number of students didn't seek help during stress and remained speechless. A careful observation of the above sources reflects both plus and minus points. Scientifically, the means to find peace and performance of religious duties help to reduce stress (Ohue et al., 2011). But, on the other hand, the study indicated that some students didn't seek help and remained speechless during stress. Despite the fact that students are frequently advised to consult with school counselors about problems during stress, only $7.1 \%$ of students followed this. Therefore, there is a need to encourage students to consult with school counselors during problems and stress, especially that stress is more common in younger and female students who stay away from family which is the main supportive source.

A research study which was conducted on 265 students at in haw University evaluated the correlation between daily life stresses and students' academic compatibility. The results indicated a negative correlation between daily life stresses and student's academic compatibility and student counselling centre must perform programs which improve student academic compatibility (Iqbal et al., 2015; Chauhan et al., 2014).

\section{Conclusion}

Students stressors must be evaluated carefully, specially stress in educational and clinical areas. The notion is to reduce stress by change and modification in stress coping strategies and to educate students who have faith and belief in their future and careers. Since, at this age, students are developing self-confidence and high levels of stress can affect their health, quality of life, academic progression and preparation to admit their future role negatively, it is highly important to concentrate on stress and its consequences and adopt suitable ways to avoid it.

\section{Acknowledgements}

The authors thank the Vice-chancellory of Shiraz University of Medical Sciences for supporting this research (Code: 842658). This manuscript is based on the research proposal by authors. The authors also thank the Clinical Research Development Center of Shiraz University of Medical Sciences for the statistical analysis.

\section{References}

Ainslie, R. C., Shafer, A., \& Reynolds, J. (1996). Mediators of adolescents' stress in a college preparatory environment. Adolescence, 31(124), 913.

Lee, J., \& Graham, A. V. (2001). Students' perception of medical school stress and their evaluation of a wellness elective. Medical 
education, 35(7), 652-659.

Elani, H. W., Allison, P. J., Kumar, R. A., Mancini, L., Lambrou, A., \& Bedos, C. (2014). A systematic review of stress in dental students. Journal of dental education, 78(2), 226-242.

Tuinman, M. A., Fleer, J., Hoekstra, H. J., Sleijfer, D. T., \& Hoekstra-Weebers, J. E. (2004). Quality of life and stress response symptoms in long-term and recent spouses of testicular cancer survivors. European Journal of cancer, 40(11), 1696-1703.

Admi, H. (1997). Nursing students' stress during the initial clinical experience. The Journal of nursing education, 36(7), 323-327.

Sheu, S., Lin, H. S., \& Hwang, S. L. (2002). Perceived stress and physio-psycho-social status of nursing students during their initial period of clinical practice: the effect of coping behaviors. International journal of nursing studies, 39(2), 165-175.

Pozos Radillo, B. E., Tórrez López, T. M., Aguilera Velasco, M. D. L. Á., Acosta Fernández, M., \& González Perez, G. J. (2008). Stressassociated factors in Mexican dentists. Brazilian oral research, 22(3), 223-228.

Nandi, M., Hazra, A., Sarkar, S., Mondal, R., \& Ghosal, M. K. (2012). Stress and its risk factors in medical students: an observational study from a medical college in India. Indian Journal of medical sciences, 66(1), 1.

Yonge, O., Myrick, F., \& Haase, M. (2002). Student nurse stress in the preceptorship experience. Nurse educator, 27(2), 84-88.

Sanaiey, N. Z. (2014). The Comparative Study of the Effectiveness of Using E-Learning, Blended Learning and Presence Learning in Continuous Medical Education. World Journal of Medical Sciences, 10(4), 488-493.

Chang, E. M., Bidewell, J. W., Huntington, A. D., Daly, J., Johnson, A., Wilson, H., ... \& Lambert, C. E. (2007). A survey of role stress, coping and health in Australian and New Zealand hospital nurses. International Journal of Nursing Studies, 44(8), 1354-1362.

Edwards, N., Saady-Habib, A., llufoye, D., Cheng, J., Lynch, S., Nguyen, K., \& Hammoudi, D. (2014). The Prevalence of Stress, Depression, and Anxiety in Medical Students.

Torshizi, L., \& Ahmadi, F. (2011). JOB STRESSORS FROM CLINICAL NURSES'PERSPECTIVE. Iran Journal of Nursing (IJN), 24(70), 49-60.

Nicolescu, L., \& Galalae, C. (2013). A systematic literature review on students 'international mobility and cultural adjustment. Management \& Marketing, 8(2), 261.

Bughi, S. A., Sumcad, J., \& Bughi, S. (2006). Effect of brief behavioural intervention program in managing stress in medical students from two southern California universities. Medical Education Online, 11, 1-8.

Brahmbhatt, K. R., Nadeera, V. P., Prasanna, K. S., \& Jayram, S. (2013). Perceived stress and sources of stress among medical undergraduates in a private medical college in Mangalore, India. International Journal of Biomedical and Advance Research, 4(2), 128-136.

Ohue, T., Moriyama, M., \& Nakaya, T. (2011). Examination of a cognitive model of stress, burnout, and intention to resign for Japanese nurses. Japan Journal of Nursing Science, 8(1), 76-86.

Iqbal, S., Gupta, S., \& Venkatarao, E. (2015). Stress, anxiety \& depression among medical undergraduate students \& their sociodemographic correlates. The Indian journal of medical research, 141(3), 354.

Chauhan, H. M., Shah, H. R., Chauhan, S. H., \& Chaudhary, S. M. (2014). Stress in medical students: A cross sectional study. International Journal of Biomedical and Advance Research, 5(6), 292-294.

Baykan, Hayriye, \& Yargic, Ilhan. (2012). Depression, anxiety disorders, quality of life and stress coping strategies in hemodialysis and continuous ambulatory peritoneal dialysispatients. Bulletin of Clinical Psychopharmacology, 22(2), 167-176. 